\title{
APRENDIZAGEM BASEADA EM PROJETOS POR MEIO DE TEXTOS DE DIVULGAÇÃO CIENTÍFICA
}

\author{
Viviane Godoi ${ }^{1}$ \\ Juliana Marques Cianni² \\ Bruna Ferreira de Almeida ${ }^{3}$ \\ Carlos Alberto Moreira Santos ${ }^{4}$ \\ Marco Antonio Carvalho Pereira ${ }^{5}$
}

\begin{abstract}
RESUMO: A Aprendizagem Baseada em Projetos ( $\mathrm{ABP}$ ) consiste em uma estratégia de aprendizagem com o intuito do desenvolvimento de competências técnicas e socio emocionais nos alunos, partindo de questões reais. Desta forma, a presente pesquisa buscou responder a seguinte pergunta: Poderia a ABP contribuir com a aprendizagem dos conteúdos de Ciências? A aplicação foi feita com 22 alunos do 70 ano do Ensino Fundamental de uma escola pública do município de Guaratinguetá (SP), divididos em quatro equipes. As equipes deveriam construir materiais didático-lúdicos a partir de textos de divulgação científica, como forma de contribuir para o processo de ensino e aprendizagem do tema: "Ecologia". Como resultado, foram desenvolvidos cinco produtos, já que uma das equipes criou dois produtos. Os produtos foram: jornal impresso, vídeo, maquete, jogos e cartilha informativa. Durante o projeto, foi possível observar o desenvolvimento de competências técnicas e socio emocionais, destacando-se criatividade, autonomia e trabalho em equipe.
\end{abstract}

Palavras-chave: Aprendizagem Baseada em Projetos. Ensino Fundamental. Divulgação Científica.

\footnotetext{
${ }^{1}$ Mestranda do Programa de Pós-Graduação em Projetos Educacionais de Ciências (PPGPE) da Escola de Engenharia de Lorena.

${ }^{2}$ Mestranda do Programa de Pós-Graduação em Projetos Educacionais de Ciências (PPGPE) da Escola de Engenharia de Lorena

${ }^{3}$ Mestranda do Programa de Pós-Graduação em Projetos Educacionais de Ciências (PPGPE) da Escola de Engenharia de Lorena

${ }^{4}$ Professor Livre Docente na Escola de Engenharia de Lorena (USP) no Programa de Pós-Graduação em Projetos Educacionais de Ciências. Doutor em Engenharia de Materiais. Mestre em Física. Graduado em Engenharia Química. E-mail: cams-eel@usp.br

${ }^{5}$ Professor Doutor na Escola de Engenharia de Lorena (USP) no Programa de Pós-Graduação em Projetos Educacionais de Ciências. Doutor em Engenharia de Produção. Mestre em Engenharia de Materiais. Graduado em Engenharia Química. E-mail: marcopereira@usp.br.
} 


\title{
PROJECT-BASED LEARNING BY SCIENTIFIC DIVULGATION TEXTS
}

\begin{abstract}
Project-Based Learning consists of an active learning strategy for the development of technical and social-emotional skills in students, based upon real issues. In such way, the present work tried to answer the following question: Could the ABP contribute to the learning of the contents of Science? The application was carried out with 22 students from the 7th grade of Elementary School of a public school at Guaratinguetá town, in São Paulo state, divided into four teams. The teams should build didactic-play materials from scientific dissemination texts, as a way to contribute to the teaching and learning process of the thematic "Ecology". As a result, five products were developed, since one of the teams developed two products. The products were: printed newspaper, video, model, games and information booklet. During the project, it was possible to observe the development of technical and socio-emotional competences, highlighting creativity, autonomy and teamwork.
\end{abstract}

Keywords: Project-Based Learning. Elementary School. Scientific divulgation.

\section{APRENDIZAJE BASADO EN PROYECTOS POR MEDIO DE TEXTOS DE DIVULGACIÓN CIENTÍFICA}

RESUMEN: El Aprendizaje Basado en Proyectos ( $A B P$ ) consiste en una estrategia de aprendizaje activa con el propósito del desarrollo de competencias técnicas y socio emocionales en los alumnos, partiendo de cuestiones reales. De esta forma, la presente investigación buscó responder la siguiente pregunta: ¿Podría la ABP contribuir con el aprendizaje de los contenidos de Ciencias? La aplicación se realizó en ocho etapas durante cuatro semanas, con 22 alumnos del séptimo año de la Enseñanza Fundamental de una escuela pública del municipio de Guaratinguetá (SP, Brasil), divididos en cuatro equipos. Los equipos deberían construir materiales didáctico-lúdicos a partir de textos de divulgación científica, como forma de contribuir al proceso de enseñanza y aprendizaje del tema "Ecología". Como resultado, se desarrollaron cinco productos, ya que uno de los equipos desarrolló dos productos. Los productos fueron: periódico impreso, Video, Maqueta, Juegos y Cartilla informativa. Durante el proyecto, fue posible observar el desarrollo de competencias técnicas y socio emocionales, destacándose creatividad, autonomía y trabajo en equipo.

Palabras clave: Aprendizaje Basado en Proyectos. Enseñanza fundamental. Divulgación Científica. 


\section{Introdução}

O letramento científico no Brasil, principalmente no que tange as esferas da Educação Básica, é muito deficiente (SASSERON; DE CARVALHO, 2008; LORENZETTI; DELIZOICOV, 2001). Face a isto, é relevante propiciar aos educandos desta esfera educacional, uma oportunidade de conhecer o ensino de ciências sob diferentes visões e estratégias educacionais. Este trabalho apresenta uma proposta realizada, no âmbito das Ciências Biológicas, que propôs a criação de um produto a fim de possibilitar a crianças o aprendizado de ciências de uma maneira lúdica e criativa, a partir de jogos, história em quadrinhos, música, teatro ou qualquer outra forma de expressão artística.

A ideia central é levar o educando a protagonizar de forma prática e efetiva seu processo de aprendizagem, proporcionar-lhe o prazer de validar o resultado de seus trabalhos a partir da interação com outras crianças e fazer com que cada um perceba a capacidade que possui de ser um agente transformador na comunidade que participa.

Desta forma, o objetivo geral deste trabalho foi, através da estratégia de Aprendizagem Baseada em Projetos, construir materiais didático-lúdicos por meio da utilização de textos de divulgação científica, como forma de contribuir para os processos de ensino e de aprendizagem do conteúdo de "Ecologia" para alunos do Ensino Fundamental II.

\section{Aprendizagem Baseada em Projetos}

Atualmente, muito se discute a importância do uso de metodologias ativas nas instituições de ensino. Para Moran (2015, p.16), as metodologias ativas proporcionam ao aluno a possibilidade do aprendizado de forma contextualizada partindo de situações reais em contraposição aos métodos considerados tradicionais que "privilegiam a transmissão de informações pelos professores". Ele também afirma que "as metodologias ativas são pontos de partida para avançar para processos mais avançados de reflexão, de integração cognitiva, de generalização, de reelaboração de novas práticas" (MORAN, 2015, p.18).

A Aprendizagem Baseada em Projetos (ABP) surgiu na década de 1960 em faculdades de medicina, visando preparar de forma mais adequada, os alunos da 
graduação para o mercado de trabalho, a partir da vivência com problemas reais que serão encontrados no cotidiano da vida profissional (POWELL; WEENK, 2003). Trata-se de uma estratégia educacional de ensino e aprendizagem centrada no aluno e baseada em três princípios do construtivismo: (i) a aprendizagem é específica do contexto; (ii) os alunos se envolvem ativamente no processo de aprendizagem; e (iii) os alunos atingem os seus objetivos através de interações sociais e de partilha de conhecimento e compreensão (COCCO, 2006).

Segundo Thomas (2000), a Aprendizagem Baseada em Projetos está inserida no contexto de metodologias ativas e consiste em um modelo que organiza o aprendizado em torno de projetos. Este mesmo autor apresenta cinco características que um projeto deve ter para ser enquadrado na estratégia de Aprendizagem Baseada em Projetos: centralidade, questão norteadora, investigação construtiva, autonomia e realismo. Destaca ainda que estes critérios não constituem uma definição específica para essa estratégia educacional, mas são concebidos para responder à seguinte questão: "O que um projeto deve ter para ser considerado uma instância de Aprendizagem Baseada em Projetos?" (THOMAS, 2000, p. 3). Além destas características, Barbosa e Moura (2013, p.63) descrevem ser importante considerar a "definição de um período de tempo para a realização do projeto", a "realização de projetos por grupos de alunos" e a "socialização dos resultados dos projetos em diversos níveis de comunicação, como a própria sala de aula, a escola e a comunidade", pontos esses que também são corroborados por Graff e Kolmos (2003) que além de explicitarem que o aluno é responsável pelo seu aprendizado, entendem que ele deve ter uma grande autonomia para decidir como realizar o projeto. Portanto, diferentemente dos métodos tradicionais de ensino, nos quais o professor é o centro do ensino, nessa metodologia o aluno é o centro, sendo ele o ator principal e ativo de sua aprendizagem; ao mesmo tempo, os professores passam a ter o papel de facilitadores do aprendizado, auxiliando quando necessário, mas permitindo que os alunos direcionem o projeto por eles mesmos.

Mills e Treagust (2003) propõem que quando aplicada Aprendizagem Baseada em Projetos não existe uma única resposta correta para a problemática proposta, pois a partir de um tema em comum, os alunos devem ter liberdade de escolha sobre o caminho a ser tomado para as suas propostas e apresentar a solução que acreditam 
ser mais viável para o problema apresentado. Além disso, para esses autores, essa estratégia ativa de aprendizagem exige, por parte dos alunos, que aprendam sobre um determinado conteúdo específico para a entrega do projeto, após a identificação do problema em situações reais, variando a complexidade do projeto, o que inevitavelmente impacta no desenvolvimento dos próprios alunos.

Neste contexto, a Aprendizagem Baseada em Projetos é aplicada na solução de problemas em um projeto aberto, para o qual não existe uma solução única. Isso é feito a partir de trabalho em equipe e da articulação entre a teoria e a prática, o que permite uma adequada combinação para o desenvolvimento de competências técnicas e transversais (FERNANDES et al, 2014; GRAFF; KOLMOS, 2003; POWELL; WEENK, 2003).

Muitas são as características que complementam a definição de Aprendizagem Baseada em Projetos, mas algumas se destacam e são indispensáveis para que se caracterize a metodologia: (i) o aluno está no centro do processo; (ii) os projetos devem ser de situações reais; (iii) o projeto deve ser realizado em equipe; e (iv) consiste em um processo ativo, colaborativo, integrado e interdisciplinar (LIMA et al, 2012; MASSON et al, 2012).

\section{Contexto do projeto}

Aprendizagem Baseada em Projetos foi aplicada, como uma estratégia educacional de aprendizagem ativa, em uma turma de 22 alunos do 70 ano do Ensino Fundamental, na disciplina de Ciências, em uma escola pública no município de Guaratinguetá, SP. A turma foi dividida quatro grupos: três deles com 6 alunos e 1 com 4 alunos.

A turma foi acompanhada em todo o projeto por uma das autoras, professora com formação em Biologia, a titular da turma. O projeto foi acompanhado de maneira parcial, por duas professoras que atuam em outras escolas públicas municipais e estaduais, mas que não estiveram no dia a dia em todas as atividades, uma delas com formação em Letras e outra em Biologia.

Cada um dos grupos deveria construir materiais didático-lúdicos sobre o tema Ecologia a partir de duas fontes principais: textos de divulgação científica e visita a um Parque Municipal. Cada um dos quatro grupos contou com um líder escolhido entre eles. Este líder foi responsável por manter a professora da turma informada dos 
acontecimentos externos à sala de aula, por meio de um relatório simplificado de acompanhamento, entregue uma vez por semana. Ele também foi responsável por relatar conflitos, quando houvesse, e que o grupo não pudesse solucionar. O projeto teve duração de quatro semanas divididas em oito etapas, conforme Quadro 1.

Quadro 1 - Etapas do desenvolvimento do projeto

\begin{tabular}{|c|l|}
\hline Etapa & \multicolumn{1}{c|}{ Atividade } \\
\hline 1 & Apresentação do projeto e divisão dos grupos em sala de aula \\
\hline 2 & Realização de uma aula expositiva acerca do tema "Ecologia \\
\hline 3 & Distribuição de textos de divulgação científica \\
\hline 4 & Realização de uma visita a um Parque Municipal \\
\hline 5 & Definição de um produto a partir dos textos e da visita ao Parque \\
\hline 6 & Construção de um produto \\
\hline 7 & Apresentação dos produtos construídos. Avaliação da classe pela professora titular. \\
\hline 8 & Aplicação de questionário para os alunos \\
\hline
\end{tabular}

Fonte: Elaboração dos Autores

\section{Desenvolvimento do projeto}

Na primeira etapa, realizada numa aula de 50 minutos, a professora da turma fez a apresentação do projeto, explicou a importância de estratégias ativas de aprendizagem e apresentou, em linhas gerais, todas as etapas do projeto. Também constituiu os grupos, mantendo os já existentes na sala na qual os alunos já vinham trabalhando durante todo o ano letivo.

Na segunda etapa, a professora ministrou uma aula expositiva sobre Ecologia e sua importância, utilizando recursos audiovisuais através de slides previamente produzidos com muitas fotos e cores para estimular o interesse dos alunos. Na terceira etapa, foram escolhidos pelas professoras textos de divulgação científica (artigos jornalísticos) extraídos da revista Galileu e de sites da Internet. A escolha foi realizada levando-se em conta a facilidade de leitura, coerência com os temas e cunho científico, todos eles relacionado ao conteúdo de ecologia.

Texto 1. O mapa da água (André Jorge, 2015);

Texto 2. Ecologia de paisagens e desenhos de parque (Portal Educação, 2012); 
Texto 3. Unidades de Conservação (Eco, 2013);

Texto 4. Observação de pássaros (Andréa Soares Pires, 2018).

Cada grupo, pôde fazer a leitura e interpretação do texto, e depois escolher o tema que mais lhes interessava, e após receberam a tarefa de iniciar a criação de estratégias para atingir o objetivo do projeto.

$\mathrm{Na}$ quarta etapa foi feita uma visita de 100 minutos, no Parque Ecológico Municipal Anthero dos Santos, situado no município de Guaratinguetá, SP, distante 10 minutos de caminhada da escola. A professora da turma, junto com outra colega da escola, acompanhou a turma em toda a visita. O objetivo da visita foi possibilitar que os alunos, mediante mediação da professora da turma, pudessem identificar numa situação real de observação algumas particularidades propostas pelos textos lidos, bem como proporcionar um ambiente extraclasse que permitisse uma maior socialização entre eles. Ao chegarem no parque, os alunos foram recebidos por um funcionário da administração que conversou com eles, ficou disponível para responder perguntas, principalmente, esclarecer dúvidas relacionadas ao trabalho de cada grupo. Em seguida, os alunos fizeram uma caminhada de observação, para fotografar e anotar detalhes do Parque que viessem a contribuir com os temas que foram escolhidos. Em seguida, os grupos sentaram juntos e analisaram como unir o contexto do Parque com os temas escolhidos. Por fim, os alunos fizeram um lanche no Parque e voltaram para a Escola.

Na quinta etapa, de volta à sala de aula, os grupos tiveram a tarefa de definir como apresentariam o conteúdo que Ihes cabiam, tendo como inspiração o texto trabalhado e como cenário, o Parque ecológico visitado. Nessa etapa, foi necessária uma interferência da professora para amenizar o conflito em um dos grupos, no qual os alunos não conseguiam entrar em consenso sobre as ideias para o Projeto e estavam tendo dificuldade com a liderança do grupo. Na sexta etapa, os grupos reuniram-se em sala de aula, a fim de colocar as ideias que já tinham surgido durante a aula prática no Parque. Houve algumas mudanças de planos como a troca da produção de um vídeo pelo grupo 2 por uma maquete. Durante todo desenvolvimento da aula, a professora da turma auxiliou os grupos na revisão dos textos e nas dúvidas que foram surgindo.

$\mathrm{Na}$ sétima etapa, foi feita a apresentação dos produtos construídos para a professora da sala e a coordenadora da escola. Cada um dos grupos teve 15 minutos 
para fazer sua apresentação e depois mais 10 minutos para responder perguntas e esclarecer dúvidas de todos os presentes na sala de aula. O Grupo 1 (Tema: Água) elaborou um jornal impresso (Figura 1) e um vídeo.

Figura 1 - Jornal Ecológico Estudantil

Jornal Ecológico Estudantil

GUARATINGUETÁ, 20 DE MAIO DE 2018.

ALUNOS VISITAM PARQUE ECOLÓGICO ANTHERO DOS SANTOS E TÊM AULA DE CONSERVAÇÃO

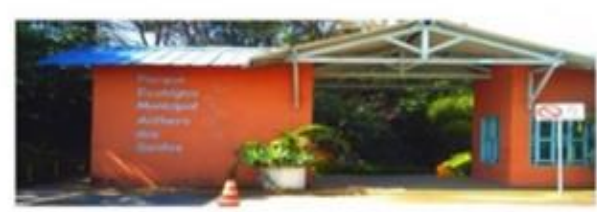

O fixo no lago

No lago percebem-se alguns tipos de lixo: copo descartivel, plástico, sacola plástica, embalagens de comida, etc. Este lixo, algumas vezes vem com a água da chuva pela canalização e na sua maioria das vezes, infelizmente, pelos visitantes.

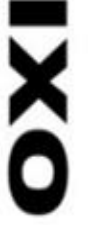

$\frac{1}{\partial}$

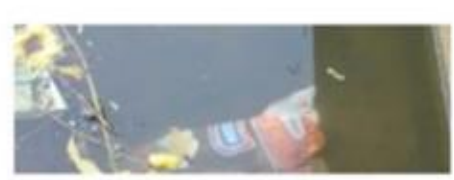

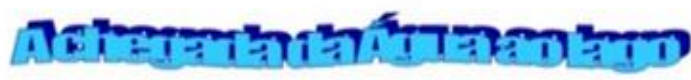

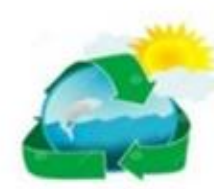

A ohsgada da toua no lago A agua do lago choga de Fortal das Colnas. portem chegada da agua ao lago; como nascentes proximas a şgua da chuma

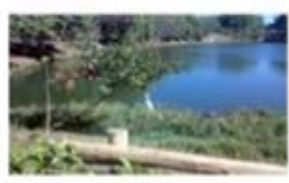

A saída da água

No lago percebe-se uma

canalização, esta canalização

está ligada diretamente ao

Rio Paraiba.

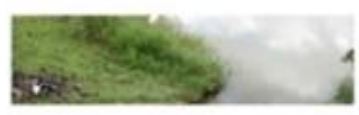

Animais no lago

No lago encontra-se uma pequena quantidade de animais. Tais como: patos, ganso, cágado carpas, bagres e tiläpias.
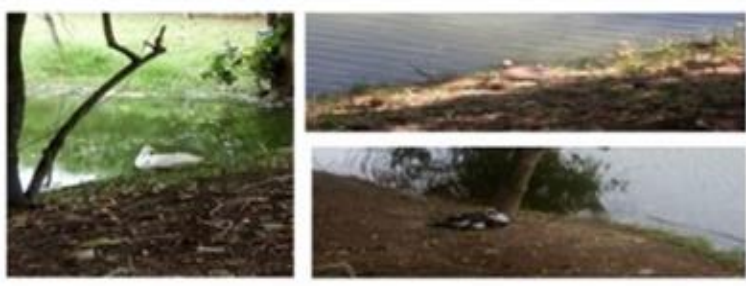

Fonte: Acervo dos autores

Tanto o jornal impresso quanto o vídeo continham informações sobre a origem da água do lago artificial existente no parque, sobre a sujeira que estava nas extremidades do lago, sobre os tipos de peixes que habitavam o lago, e sobre os pássaros e outros animais que utilizam o lago para "pescar". O Grupo 2 (Tema: Paisagem Ecológica) apresentou uma maquete construída sobre uma placa de isopor (Figura 2) dividida em duas partes: uma metade mostrava o local onde hoje está o parque antes de sua construção, quando havia só um banhado; a outra metade mostrava como está o parque na atualidade, com o lago, árvores e um local de caminhada. 


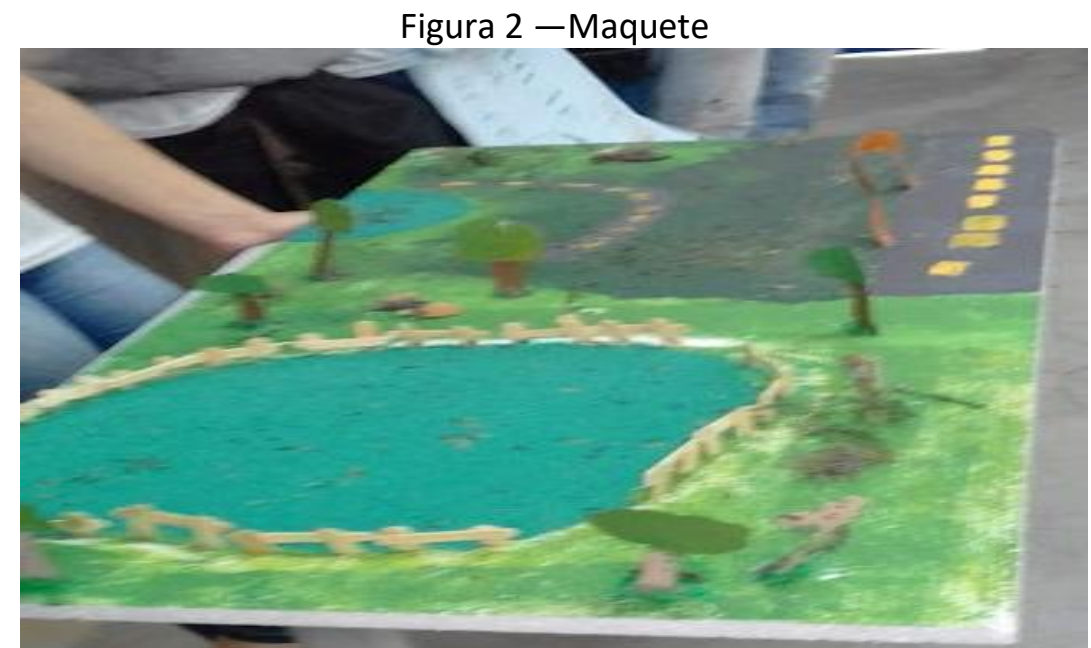

Fonte: Acervo dos autores

O Grupo 3 (Tema: Unidades de Conservação) construiu o “Jogo da Conservação" (Figura 3) com perguntas e respostas, e utilizaram o texto base, entregue na terceira etapa, para formular as perguntas e deixaram claro na apresentação que os jogadores só conseguiriam jogar depois de fazerem a leitura do referido texto, pois as perguntas eram específicas.

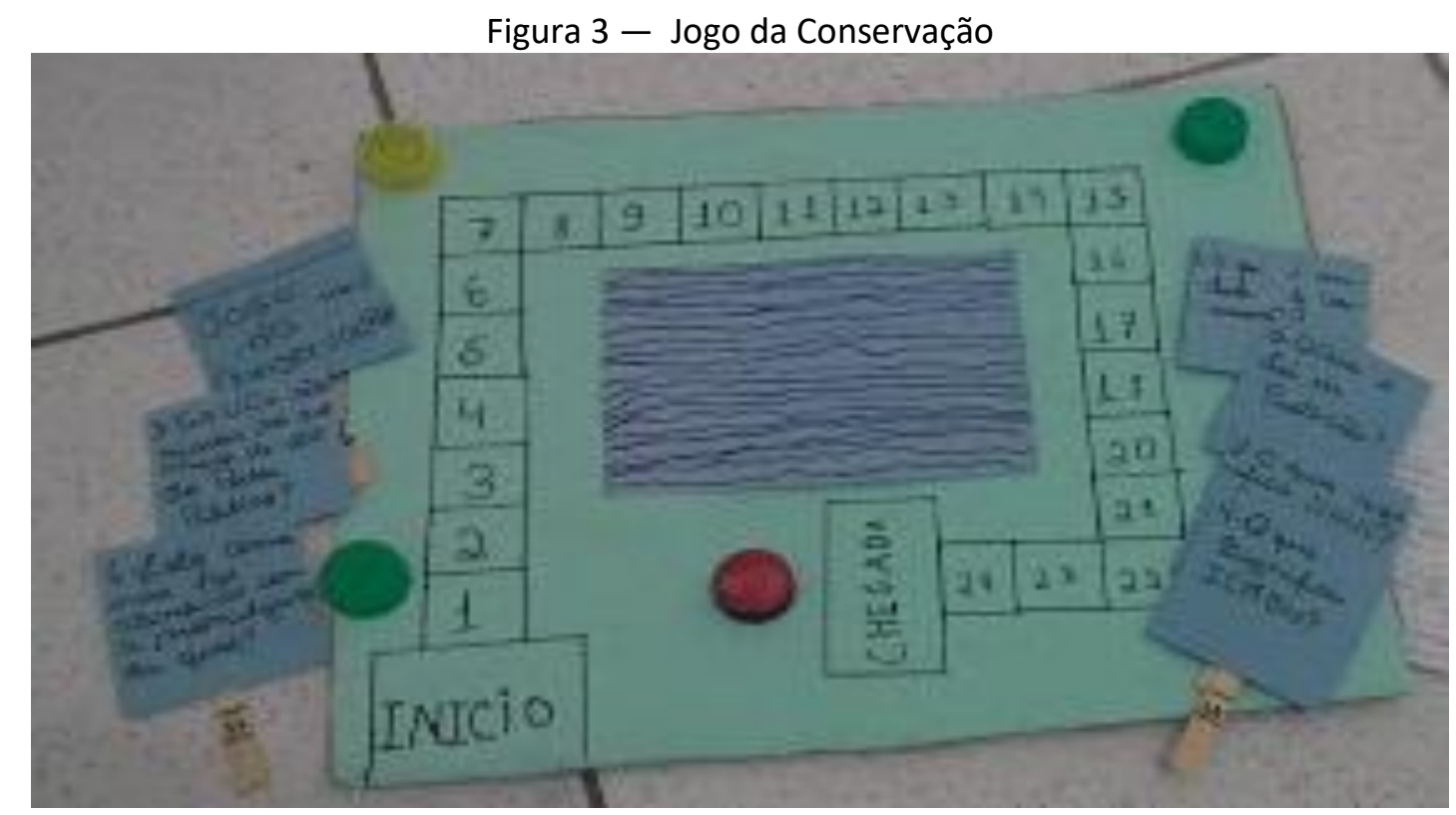

Fonte: Acervo dos autores 
O Grupo 4 (Tema: Observação de Pássaros) produziu uma cartilha com fotos e a identificação científica de alguns pássaros do parque e um jogo com perguntas e respostas sobre as aves que existem na cidade de Guaratinguetá (Figura 4). Para pesquisa sobre os pássaros que mais frequentes na região, os alunos utilizaram informações de uma Exposição de "Aves de Guaratinguetá", que estava ocorrendo, na época, no Espaço Cultural do Buriti Shopping.

$\mathrm{Na}$ conclusão das apresentações dos produtos, notou-se que os grupos, em sua maioria, atingiram os objetivos de relacionar o texto-base entregue com aspectos da visita ao Parque Ecológico. Na ocasião da visita ao Parque, os alunos já possuíam subsídios de cunho ecológico para observar o Parque de forma atenta e crítica, e assim o fizeram, pois levantaram questionamentos sobre sua função, que deveria, na visão deles, ser um ambiente coletivo e de preservação da natureza, suas plantas e animais.

Figura 4 - Jogo e cartilha sobre aves do município

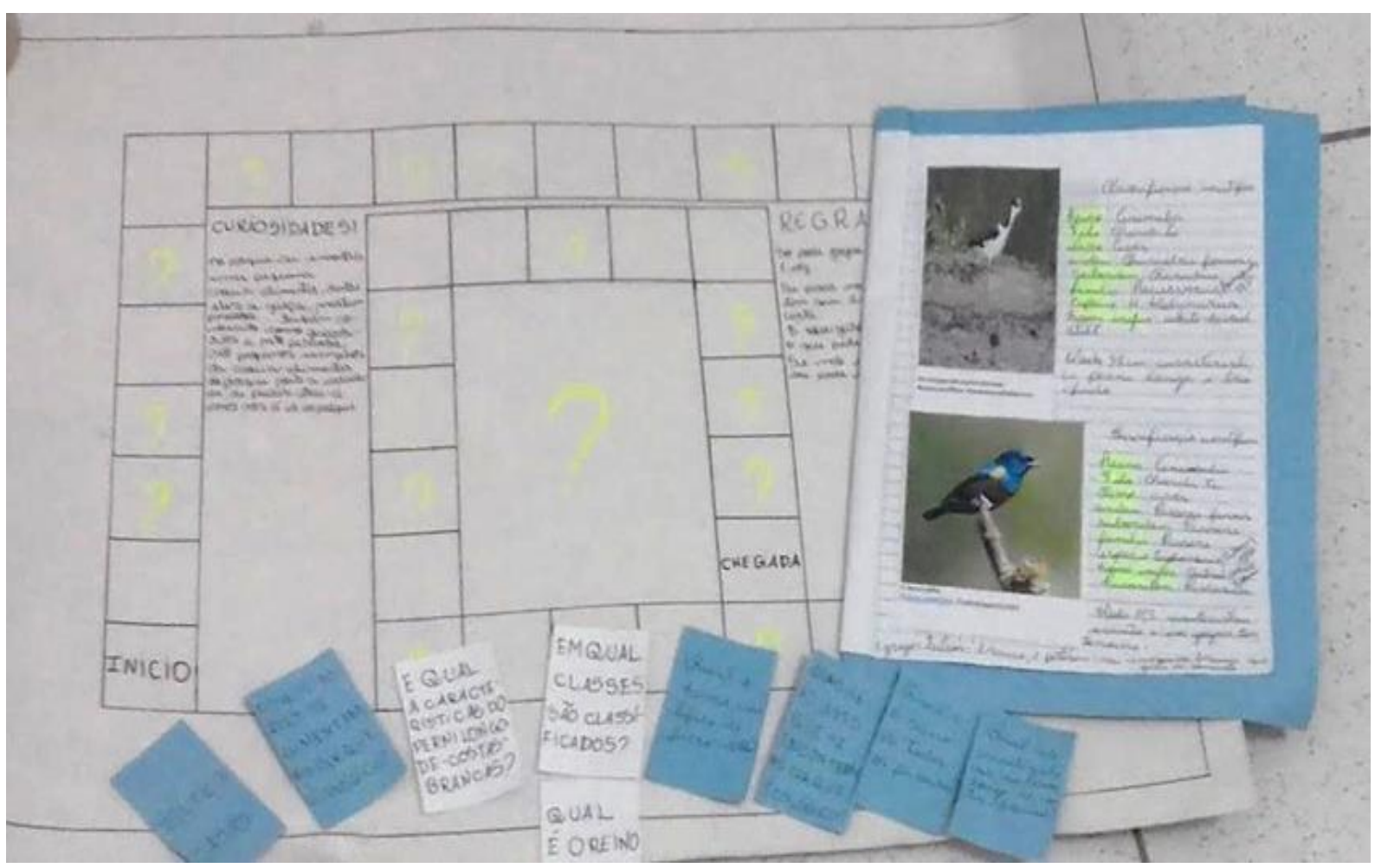

Fonte: Acervo dos autores 
Os alunos consideraram que o Parque estava mais voltado ao lazer e prática de atividades físicas, do que a um parque ecológico. Em suas observações, eles propuseram sugestões de intervenções, como locais para se colocar lixeiras ecológicas, placas com nome das árvores e tipos de animais presentes no local.

Uma avaliação das apresentações foi feita pela professora da turma. A coordenadora fez questionamentos aos grupos, mas não os avaliou, por não ter acompanhado todo o processo.

Na oitava e última etapa, foi feita a aplicação de um questionário para que os alunos avaliassem o projeto, bem como a participação de cada um no projeto.

\section{Resultados e discussão}

\section{Avaliação feita pelas professoras}

Para avaliação das atividades desenvolvidas pelos alunos durante a realização do projeto, foram utilizados três formulários. Os dois primeiros foram preenchidos somente pela professora da turma que acompanhou os alunos durante todo o projeto. O terceiro foi preenchido pela professora titular e as outras duas professoras que acompanharam parcialmente o projeto.

O primeiro formulário teve como objetivo avaliar os grupos durante todo o processo, verificando a cooperação entre os alunos para o desenvolvimento do trabalho em equipe e a responsabilidade com o cumprimento dos prazos estabelecidos. A Tabela 1 apresenta o resultado das competências avaliadas a partir de uma escala com três fatores: Desenvolvido (100\%); Parcialmente desenvolvido (50\%); Não desenvolvido (10\%).

Tabela 1 - Avaliação das competências dos grupos durante o processo

\begin{tabular}{ccccc}
\hline GRUPO & $\mathbf{1}$ & $\mathbf{2}$ & $\mathbf{3}$ & $\mathbf{4}$ \\
\hline Trabalho em equipe & $100 \%$ & $10 \%$ & $100 \%$ & $100 \%$ \\
Cooperação e responsabilidade & $100 \%$ & $10 \%$ & $50 \%$ & $100 \%$ \\
Cumprimento dos prazos & $100 \%$ & $50 \%$ & $100 \%$ & $100 \%$ \\
\hline
\end{tabular}

Fonte: autores 
Os resultados da tabela 1 revelam que, de forma geral, os grupos apresentaram um bom desenvolvimento das competências avaliadas, exceto o Grupo 2, que teve dificuldade de colaboração, acarretando o não cumprimento dos prazos e na necessidade de intervenção da professora para o desenvolvimento do trabalho em equipe. Neste grupo, houve muitas desavenças, pois alguns queriam gravar um vídeo no estilo Youtuber e outros a produção da maquete. Após várias intervenções realizadas pela professora, a maquete do grupo só foi finalizada com ajuda dos demais alunos da sala.

O segundo formulário teve como objetivo avaliar a apresentação do produto pelos grupos. A escala utilizada foi a mesma da tabela 1 e os resultados encontram-se na tabela 2. Os grupos apresentaram níveis de organização e desenvoltura positivos, com exceção do Grupo 2 em função das dificuldades já descritas.

Tabela 2 - Apresentação do produto pelos grupos

\begin{tabular}{ccccc}
\hline GRUPO & $\mathbf{1}$ & $\mathbf{2}$ & $\mathbf{3}$ & $\mathbf{4}$ \\
\hline Organização do grupo & $100 \%$ & $10 \%$ & $100 \%$ & $100 \%$ \\
Utilização do tempo & $100 \%$ & $10 \%$ & $50 \%$ & $100 \%$ \\
Desenvoltura & $100 \%$ & $50 \%$ & $100 \%$ & $100 \%$ \\
\hline
\end{tabular}

Fonte: Elaborado pelos autores

O terceiro formulário teve como objetivo avaliar os produtos didático-lúdicos produzidos pelos alunos. A tabela 3 apresenta os aspectos avaliados e o desenvolvimento de cada um dos grupos, considerando a mesma escala da tabela 1.

Tabela 3 - Avaliação do desenvolvimento dos grupos nos produtos didático-lúdicos produzidos

\begin{tabular}{ccccc}
\hline GRUPOS & $\mathbf{1}$ & $\mathbf{2}$ & $\mathbf{3}$ & $\mathbf{4}$ \\
\hline Clareza do texto & $100 \%$ & $50 \%$ & $100 \%$ & $100 \%$ \\
$\begin{array}{c}\text { Criatividade na execução do projeto } \\
\text { Pertinência de relação entre o texto e o }\end{array}$ & $100 \%$ & $50 \%$ & $100 \%$ & $50 \%$ \\
Parque & $100 \%$ & $50 \%$ & $50 \%$ & $100 \%$ \\
Abordagem dos conceitos & $100 \%$ & $50 \%$ & $50 \%$ & $100 \%$ \\
Resolução do problema & $100 \%$ & $50 \%$ & $100 \%$ & $100 \%$ \\
Desenvoltura & $100 \%$ & $50 \%$ & $100 \%$ & $100 \%$ \\
\hline
\end{tabular}

Fonte: Elaborado pelos autores 


\section{Avaliação feita pelos alunos}

A avaliação da aplicação do método de Aprendizagem Baseada em Projetos foi feita pelos alunos, na oitava etapa, a partir de cinco questões. Dezoito foram os alunos que responderam.

A primeira questão "Você considera o texto científico que utilizou no seu trabalho?" tinha o objetivo de identificar como os alunos avaliavam os textos disponibilizados para o desenvolvimento da metodologia. A Figura 5 apresenta, na visão dos alunos, a percepção deles em relação dos textos e percebe-se a maioria considerou de fácil ou média compreensão. Este resultado pode estar atrelado ao fato de que se trata de temas atuais e presentes no cotidiano, bem como por se tratar de uma leitura que apesar de conter palavras de cunho científico tinha por função agregar conhecimento, sem trazer dificuldades de entendimento.

Figura 5-Grau de Compreensão do texto científico pelos alunos

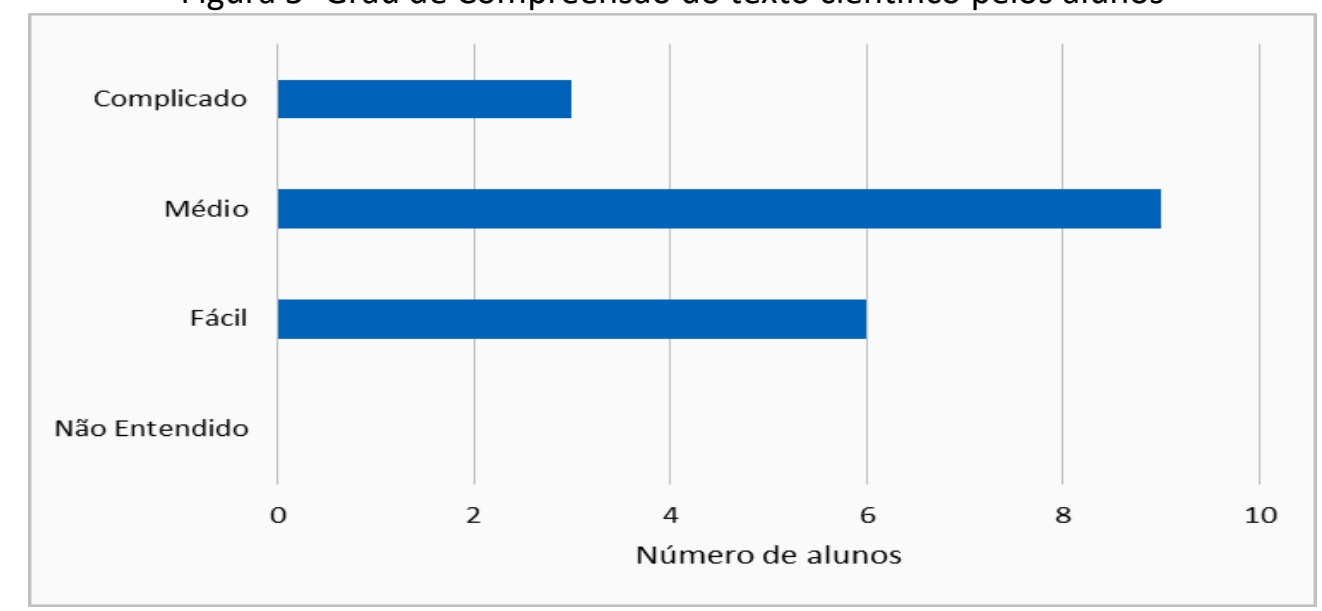

Fonte: Elaborado pelos autores

A segunda questão "O que você achou do projeto?" tinha o objetivo de verificar se a metodologia despertou o interesse dos educandos de forma motivadora. A Figura 6 apresenta os resultados, que apontam como motivadora a utilização da metodologia de Aprendizagem Baseada em Projetos para maioria dos alunos. 
Figura 6- Opinião dos alunos sobre o projeto

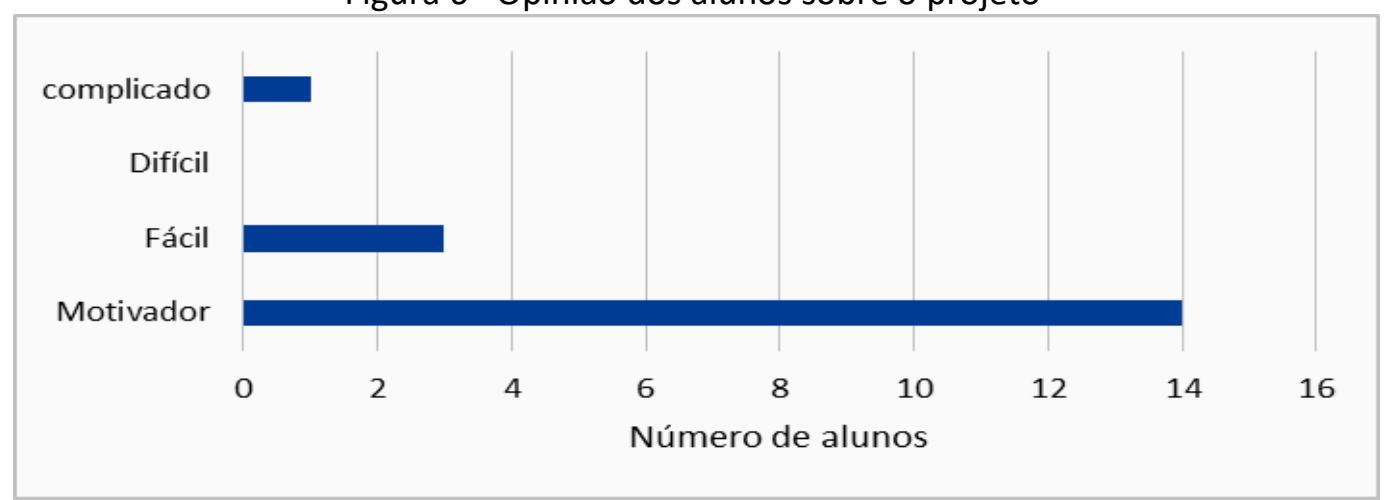

Fonte: Elaborado pelos autores

A terceira questão teve por finalidade avaliar se o trabalho em grupo havia contribuído para a resolução do problema e a produção do produto. Os resultados mostrados na Figura 7 revelam que a maioria dos alunos entendeu que sim, ou seja, que trabalhar em grupo favoreceu a obtenção do resultado obtido. Somente dois alunos discordaram disso.

Figura 7- Importância do trabalho em grupo

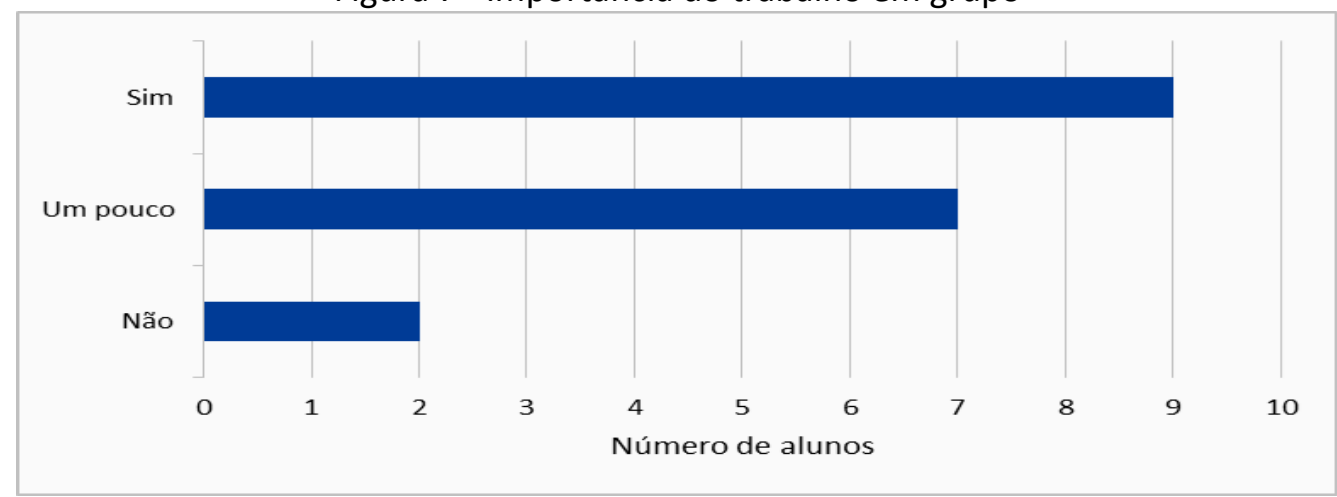

Fonte: Elaborado pelos autores

A quarta questão "A pesquisa proporcionou que você entendesse o texto e a proposta sem o auxílio da professora da classe?" tinha o objetivo de avaliar a autonomia dos alunos durante a realização do projeto. Os resultados mostrados na Figura 8 revelam que a maioria dos alunos conseguiu desenvolver as atividades de forma autônoma, porém quatro deles, em algum momento, precisaram da ajuda da professora ou de colegas de diferentes grupos. 
Figura 8- Percepção dos alunos sobre autonomia

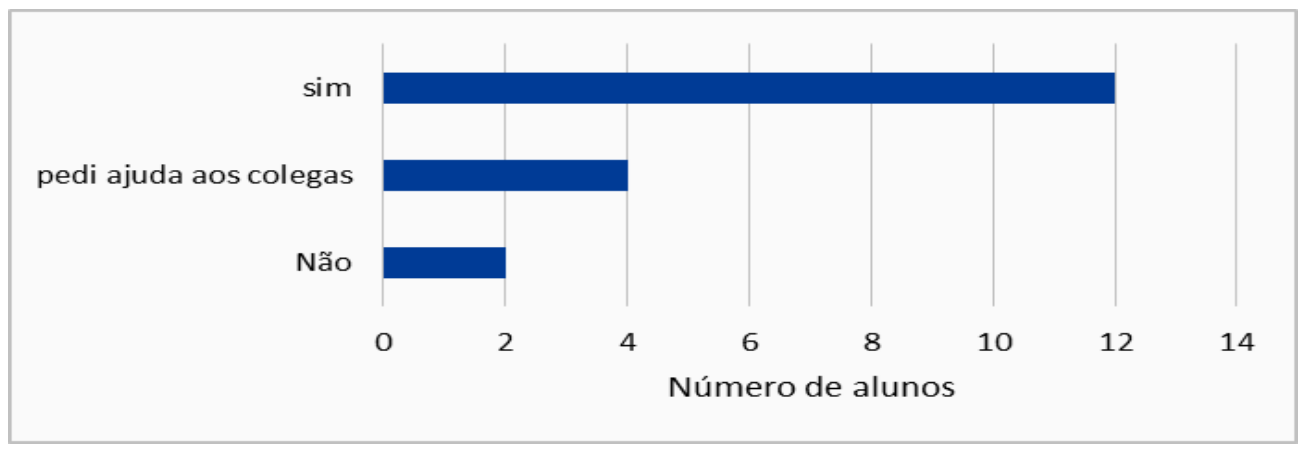

Fonte: Elaborado pelos autores

A quinta questão "Quem era você dentro do grupo?" visava possibilitar aos alunos uma autoavaliação da sua participação no desenvolvimento do projeto. Os resultados mostrados na Figura 9 revelam que pouco mais da metade dos alunos se posicionou como "conciliador" e "o que faz".

Figura 9- Perfil dos alunos no projeto

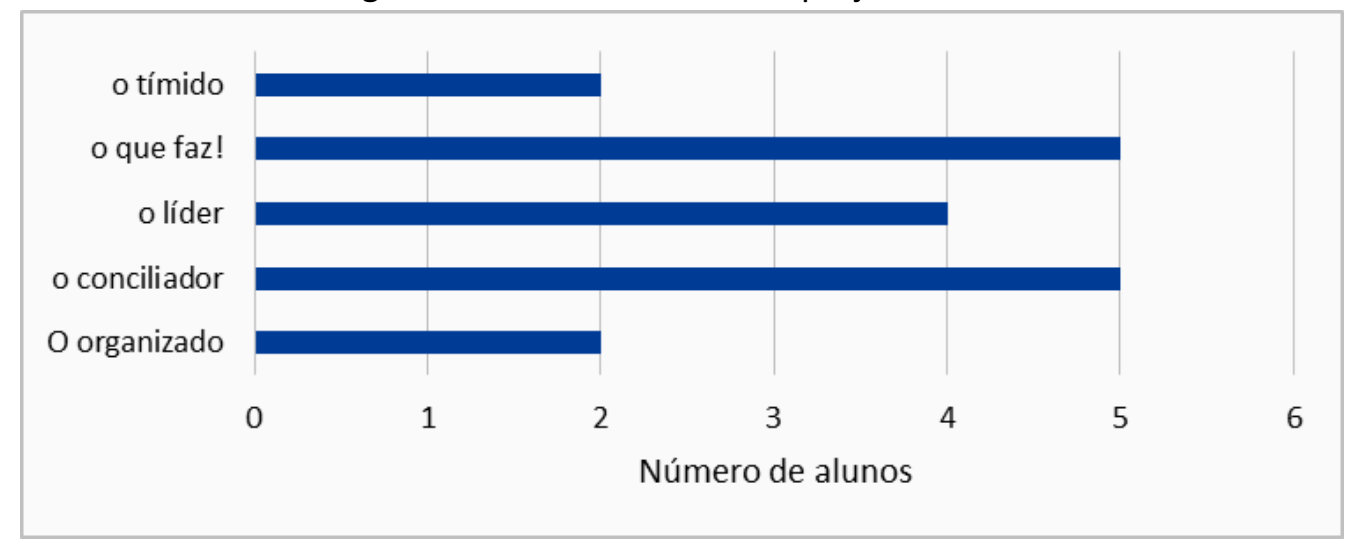

Fonte: Elaborado pelos autores

Estes resultados podem ser atribuídos à participação ativa dos alunos durante o desenvolvimento das atividades e na resolução dos problemas que surgiram ao longo do processo. 


\section{Considerações finais}

De acordo com a avaliação da metodologia realizada pelos alunos, percebe-se que a prática da Aprendizagem Baseada em Projetos se mostrou eficaz no que tange a motivação e a consolidação de papéis sociais intrínsecos no projeto, trazendo para a realidade bases organizacionais cognitivas para a prática de diversas atividades construtivas em sociedade.

Entende-se que ensino e aprendizagem são práticas complexas e que a aplicação do método de Aprendizagem Baseada em Projetos e divulgação científica por si só não conduzirá a resultados instantâneos, mas que a continuidade da prática dessa metodologia em sala de aula e a sua divulgação dentro e fora da Escola, podem proporcionar intervenções de outros professores em outras disciplinas e trazer assim metodologias comprovadamente úteis para que o aluno se torne protagonista em sala de aula e na sua própria vida.

Em síntese, o método Aprendizagem Baseada em Projetos unido a utilização de textos científicos foi bastante eficaz por apresentar resultados positivos quanto a aprendizagem dos alunos, desenvoltura nas apresentações, senso de companheirismo, senso crítico nas leituras e criou-se discussões em sala de aula sobre os temas.

Sendo assim, houve um interesse por parte dos alunos em dar prosseguimento nas atividades, com sugestões de aplicação no Parque Ecológico, seja na implantação de lixeiras ecológicas, divulgação de informações sobre o Parque via internet, já que eles receberam poucas informações e tiveram que buscá-las em outras fontes.

\section{Referências}

BARBOSA. E. F., MOURA. D. G. Metodologias ativas de aprendizagem na Educação Profissional e Tecnológica. B. Tec. Senac, Rio de Janeiro, v. 39, n. 2, p. 48-67, maio/ago., 2013.

COCCO, S. Student leadership development: The contribution of project-based learning (Unpublished Master's thesis). Royal Roads University, Victoria, BC, Canada. 2006. 
PORTAL EDUCAÇÃO. Ecologia de paisagem e desenhos de parque. Disponível em: https://www.portaleducacao.com.br/conteúdo/ artigos/biologia/ecologia-dapaisagem-e-desenho-de-parques/19381/. Acesso em: 24 out 2018.

FERNANDES, S., MESQUITA, D., FLORES, M. A.; LIMA, R. M. Engaging students in learning: findings from a study of project-led education. European Journal of Engineering Education, v. 39, n. 1, p. 55-67, 2014.

GRAFF, E.; KOLMOS, A. Characteristics of Problem-Based Learning". International Journal of Engineering Education, v. 19, n. 5, p. 657-662, 2003.

LIMA, R. M.; SILVA, J. M.; JANSSEN, N.; MONTEIRO, S. B. S.; SOUZA, J. C. F. Projectbased learning course design: a service design approach. International Journal.

Services and Operations Management, v. 11, n. 3, 2012.

LORENZETTI. L, DELIZOICOV. D Alfabetização científica no contexto das séries iniciais. Rev Ensaio - Pesquisa em Educação em Ciências, Belo Horizonte, v. 03, n. 1, p. 45-61, jan./jun., 2001. Disponível em: http://www.scielo.br/pdf/epec/v3n1/1983-2117epec-3-01-00045.pdf. Acesso em: 04 abr. 2019.

MASSON, T. J.; MIRANDA, L. F.; MUNHOZ, A. H.; CASTANHEIRA, A. M. P. Metodologia de ensino: aprendizagem baseada em projetos (PBL). In: CONGRESSO BRASILEIRO DE EDUCAÇÃO EM ENGENHARIA (COBENGE), 40., 2012. Anais [...]. Belém, 2012.

MILLS, J. E., TREAGUST, D. F. Engineering education: is Problem-Based or ProjectBased Learning the Answer?. Australasian Journal of Engineering Education, 2003. Disponivel em: http://www.engineersmedia.com.au/journals/aaee/a2index.html. Acesso em: 01 maio 2019

MORAN. J. M. Mudando a educação com metodologias ativas. 2015. Disponível em: http://www2.eca.usp.br/moran/wp-content/uploads/2013/12/mudando_moran.pdf. Acesso em: 04 abr. 2019.

SÃO PAULO. Observação de aves pode contribuir com a conservação e gerar dados científicos. Iflorestal, 2018. Disponível em:

http://iflorestal.sp.gov.br/2018/05/29/observacao-de-aves-pode-contribuir-com-aconservacao-e-gerar-dados-cientificos/. Acesso em: 24 out. 2018.

O MAPA DA ÁGUA. Revista Galileu, São Paulo, n. 227, p. 16, novembro, 2015.

OECO. O que são unidades de conservação. Dicionário ambiental. ((o)) eco, Rio de Janeiro, abr. 2013. Disponível em: http://www.oeco.org.br/dicionario-

ambiental/27099-o-que-sao-unidades-de-conservacao/. Acesso em: 26 out. 2018. 
POWELL, P. C.; WEENK, W. Project-led engineering education. Utrecht: Lemma Publishers, 2003.

SASSERON. L. H., DE CARVALHO A. M. P. Almejando a alfabetização científica no ensino fundamental: a proposição e a procura de indicadores do processo. Rev. Investigações em Ensino de Ciências. v. 13, n. 3, p. 333-352. 2008. Disponível em: https://www.if.ufrgs.br/cref/ojs/index.php/ienci/article/view/445/263. Acesso em: 04 abr. 2019.

THOMAS. J. W. A review of research on Project-Based Learning. 2000. Disponível em: http://www.ydae.purdue.edu/LCT/HBCU/documents/AReviewofResearchof ProjectBasedLearning.pdf. Acesso em: 05 abr. 2018.

Enviado em: 12/05/2019

Aprovado em: 08/02/2020 